\title{
Population structure and host-plant specialization in two Scaptodrosophila flower-breeding species
}

\author{
JSF Barker \\ School of Rural Science and Agriculture, University of New England, Armidale NSW 2351, Australia
}

\begin{abstract}
In contrast to phytophagous insect species, little attention has been paid to the possibility of host races in the Drosophilidae, although flower-breeding species, where courtship and mating take place on the flowers, are likely candidates. Two species of Scaptodrosophila, S. hibisci and S. aclinata, are restricted to flowers of Hibiscus species (section Furcaria), and the Furcaria specialization likely predated the separation of $S$. hibisci and $S$. aclinata. In all, 20 microsatellite loci were analysed in nine populations of $S$. hibisci and five of $S$. aclinata. For two pairs of $S$. hibisci populations in close proximity, but breeding on different Hibiscus species, differentiation between the populations of each of these pairs was similar to that between the populations that were from the same Hibiscus species, but geographically distant, suggesting the early stages of host-
\end{abstract}

race formation. Genetic variability was significantly less in $S$. aclinata than in $S$. hibisci, suggesting greater drift effects in the former. However, of 253 alleles detected, 82 were present in both species, 160 in $S$. hibisci only and 11 in $S$. aclinata only, indicating that $S$. aclinata was derived from S. hibisci, following a strong bottleneck at the time of separation - possibly 40000 years BP. Analyses and interpretation of Hardy-Weinberg equilibrium and $F$ statistics needed to account for null alleles known to be present at eight loci in S. hibisci, and possibly present at other loci. The results emphasize the need for caution in studies where the presence of null alleles is inferred only from population data. Heredity (2005) 94, 129-138. doi:10.1038/sj.hdy.6800592 Published online 8 September 2004

Keywords: Scaptodrosophila; flower breeders; host races; null alleles; population structure; microsatellites

\section{Introduction}

Insect species with host races occurring on different plant species have provided model systems for study of the evolution of specialization and speciation. Some cases of host-race formation, where new hosts have been introduced into the range of the insect within historical times, are well documented (eg the tephritid fly Rhagoletis pomonella - Feder et al, 1998). Much of the interest in these systems has been in the context of sympatric speciation, where it is assumed that specialization on different, but sympatric host-plant species may result indirectly in significant reproductive isolation (Via, 2001; Berlocher and Feder, 2002). In many other cases, insect species have been found to comprise populations that are locally adapted (specialized) to different plant species (Funk et al, 2002; see reviews and references in Mopper and Strauss, 1998). Where there is this high level of host-plant specialization, these species allow detailed analyses of its genetic basis - genetic differentiation, host-plant preferences, mate choice and fitness on the different hosts (eg Janz et al, 2001; Thomas et al, 2003).

In contrast to the phytophagous insect species where host races commonly have been found, most species of the Drosophilidae are saprophagous, feeding on yeasts and bacteria and the decaying tissue of plants and fungi.

Correspondence: Dr JSF Barker, School of Rural Science and Agriculture, University of New England, Armidale NSW 2351, Australia.

E-mail: sbarker@pobox.une.edu.au

Received 28 March 2003; accepted 21 July 2004; published online 8 September 2004
Among such species, most are generalists with unknown breeding sites, and only D. mojavensis is known to have evolved host races (Etges, 2002). On the other hand, species that breed in the flowers of more than one plant species may provide more opportunity for the evolution of host-plant specialization. Two closely related species of Scaptodrosophila, S. hibisci (Bock in Cook et al, 1977) and S. aclinata McEvey and Barker, 2001 have been recorded breeding in flowers of Hibiscus species in Australia, the former in five species in eastern Australia (Starmer et al, 1997; Wolf et al, 2000a) and the latter in 11 species in the Northern Territory (Wolf et al, 2000a; JSF Barker, unpublished). As both Scaptodrosophila species show an apparently strict host-plant association with endemic Hibiscus species of the section Furcaria (Barker, 2003), but each uses a range of different Hibiscus species (only $H$. meraukensis being common to both), it seems likely that Furcaria specialization predated the speciation of $S$. hibisci and S. aclinata. As courtship and mating take place on the flowers, adults could potentially respond to different physical or chemical cues from the flowers of different Hibiscus species, while larval growth and survival may be subject to differential selection by host-plant chemistry. Thus, further specialization may have evolved within each species, leading to genetic differentiation and host-race formation on different Hibiscus species.

As compared with the genus Drosophila, very little is known of the biology and genetics of Scaptodrosophila species, but our already completed studies of S. hibisci include ecological aspects, quantitative genetic analyses and reproductive biology (Starmer et al, 1997, 1998, 2000; Polak et al, 1998, 2001; Wolf et al, 2000a, b). Both S. hibisci 
and S. aclinata have fragmented, patchy distributions, with distances between neighbouring populations ranging from 1 to $2 \mathrm{~km}$ to probably $100 \mathrm{~km}$ or more. The distribution of $S$. hibisci is broader than that of $S$. aclinata (McEvey and Barker, 2001), but for both species, local population sizes may vary by orders of magnitude, as the breeding habitat at a locality varies from just one or two to hundreds of plants.

I present here a comparative analysis of population structure in the two species and tests for host-plant specialization in $S$. hibisci, based on microsatellite assay of nine populations of $S$. hibisci and five of S. aclinata. Prior to these population assays, segregation studies had shown null alleles to be present at a number of the microsatellite loci (Wilson et al, unpublished), and their treatment in the analyses has been given special consideration.

\section{Materials and methods}

Flies were collected directly from Hibiscus flowers in the field, and either put immediately into absolute ethanol, or kept alive in vials with sugar-agar medium until return to the laboratory, where they were frozen at $-80^{\circ} \mathrm{C}$. The collection localities and Hibiscus species at each are shown in Figure 1.

DNA extraction and microsatellite typing for 21 males and 21 females from each population were performed using the protocols of Wilson et al (2002) that were developed for S. hibisci. Of the 20 loci assayed, five (Sh9, Sh72, Sh74, Sh78 and Sh89) are X linked in S. hibisci (Wilson et al, 2002), and 16 (Sh8i, Sh8ii, Sh9, Sh29c, Sh34d, Sh36c, Sh38d, Sh49, Sh74, Sh81, Sh88, Sh88+ , Sh89, Sh90, Sh90 ${ }^{+}$and Sh94) have null alleles segregating in one or more populations of S. hibisci (14 identified in Wilson et al, (unpublished) and two more in this paper). Only Sh9, Sh36c and Sh90 had null alleles in S. aclinata (reported here).

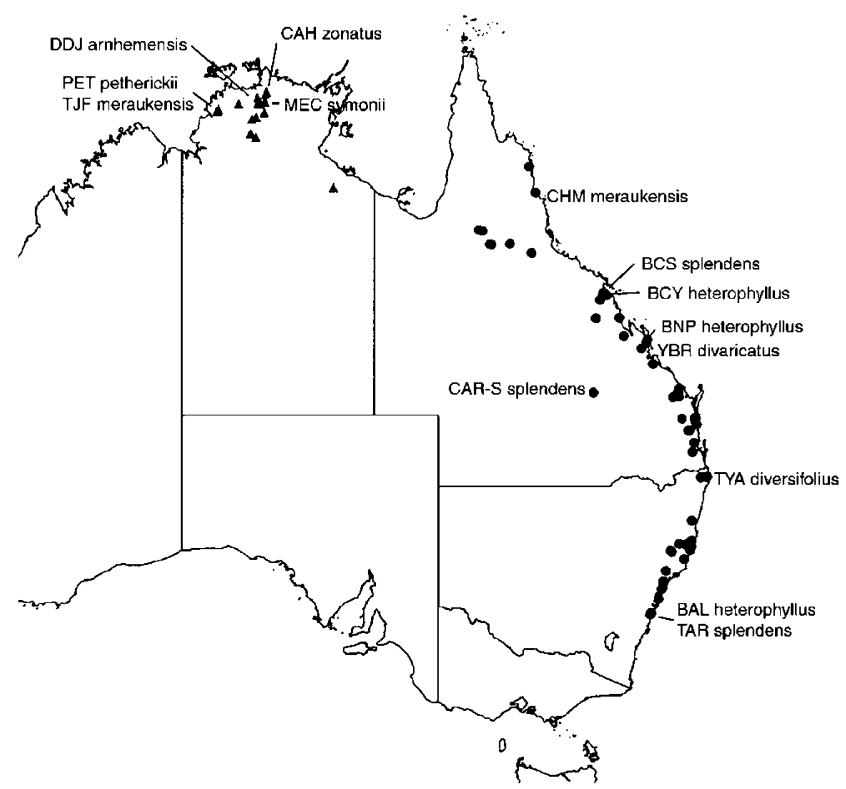

Figure 1 Localities where S. hibisci $(\bullet)$ and S. aclinata $(\boldsymbol{\Delta})$ have been collected. Populations assayed here indicated by code name and Hibiscus species at that locality.
Allele frequency and heterozygosity

For those autosomal loci where null homozygotes were segregating, genotype and allele frequencies were estimated using the computer program GENEPOP Version 3.3, option 8,1 (Raymond and Rousset, 1995), separately for each population where null homozygotes were detected. For the X-linked loci, where there were null individuals in males only in any population (Sh9 in three populations of $S$. hibisci) or none segregating, allele frequencies were computed directly. Where null females were present (Sh74 and Sh89 in S. hibisci), GENEPOP was used to estimate genotype and allele frequencies for females, and overall (sex combined) allele frequencies were then computed. Thus, for seven loci in $S$. hibisci (Sh8ii, Sh34d, Sh36c, Sh74, Sh88+, Sh89 and Sh90) and two in S. aclinata (Sh36c and Sh90), Hardy-Weinberg equilibrium is assumed for the estimation of null heterozygote frequencies.

Tests for deviations from Hardy-Weinberg equilibrium were carried out using the exact tests of GENEPOP, with significance levels for each test determined by applying the sequential Bonferroni procedure (Hochberg, 1988; Lessios, 1992) over all loci within each population to the probability estimates calculated by GENEPOP. As the raw genotype data were used for these tests, estimated deviations from Hardy-Weinberg equilibrium will be inflated for those loci where null homozygotes were segregating. The number of alleles per locus (all loci) and observed heterozygosity (for the 12 loci where no null homozygotes were detected in any population) were compared among populations of each species with Kruskal-Wallis analysis of variance (Sokal and Rohlf, 1981).

\section{Statistical analyses}

Tests for pairwise linkage (genotypic) disequilibria, separately for each population and overall, were carried out using GENEPOP, and then applying the sequential Bonferroni procedure over the pairwise tests to determine significance levels. Genotypic differentiation among populations was tested using GENEPOP, both for overall and pairwise differentiation, with the sequential Bonferroni procedure applied over population pairs for the latter in determining significance levels.

Two of the microsatellites (Sh8i and Sh8ii) are juxtaposed, being separated by 150 base pairs (Wilson et al, 2002). The allele size range for microsatellites is generally presumed to be constrained (Nauta and Weissing, 1996), and juxtaposed microsatellites might be expected to provide insights into the mechanisms of any such constraints. To determine any association of allele sizes at these two loci, haplotypes were estimated using the method of Stephens et al (2001), as implemented in the program PHASE. The correlation between allele sizes of the two loci in the haplotypes was computed, and a permutation test was carried out to compare the observed covariance of the repeat numbers with that expected by chance (Pritchard and Feldman, 1996).

For the loci where no null homozygotes were detected in any population, F-statistics and their significance were determined using FSTAT Version 2.9.3 (Goudet, 2001), again with the sequential Bonferroni procedure applied over loci in deriving significance levels. F-statistics for 
loci with null alleles segregating were computed using the methods of Weir and Cockerham (1984), as implemented in the computer program DIPLOID (Weir, 1990), but with this program adapted (B Tier, personal communication) for input of the numbers of each genotype at each locus (program diplinta.f available at http://ansc.une.edu.au/ansc/genetics/ - link through Barker JSF). The genotype numbers used were those estimated as above, accounting for null homozygotes.

Mean gene diversity (ie expected heterozygosity - computed following correction for null heterozygote frequencies) for each locus and for each population and the $D_{\mathrm{A}}$ distances among populations (Nei et al, 1983) were obtained using the DISPAN program ( $\mathrm{T}$ Ota, personal communication). As Takezaki and Nei (1996) showed that this distance is generally the best for inferring the correct topology, it was used to construct a neighbour-joining tree including both species (Saitou and Nei, 1987), using the DISPAN program.

Isolation by distance was tested using data on the 12 loci in S. hibisci and 10 in S. aclinata where no null homozygotes were detected. Estimates of $\theta$ (Weir and Cockerham, 1984) for each pair of populations were computed using the FSTAT program, and pairwise $\theta$ / $(1-\theta)$ values were then regressed on log (geographic distance) between each pair of populations (Rousset, 1997), and the significance of the association determined using Mantel's (1967) permutation test.

Given the patchy distribution of the host plants and the variation in the number of plants at each locality, the BOTTLENECK program (Cornuet and Luikart, 1996) was applied to determine if there had been past bottlenecks in population size at any locality. In this analysis, only those loci that did not deviate from HardyWeinberg equilibrium in each population were used, and for the TPM (two-phase model) the options recommended by Piry et al (1999) were applied.

\section{Divergence time of the two species}

Genetic distances between the two species were estimated for Nei's standard distance $\left(D_{\mathrm{S}}-\mathrm{Nei}, 1972,1978\right)$ and the Tomiuk and Loeschcke distance $\left(D_{\mathrm{TL}}-\right.$ Tomiuk and Loeschcke, 1991, 1995), using the POPDIST program available at http://genetics.sh.dk/bg/popgen. Takezaki and Nei (1996) showed that $D_{S}$ was more appropriate than other measures for estimating evolutionary time, while Tomiuk et al (1998) found $D_{\mathrm{TL}}$ to be more stable and more closely correlated linearly with evolutionary time than $D_{\mathrm{S}}$. Two approaches were used with the 17 loci assayed in both species: (i) including all 14 populations, and computing the average of the 45 interspecific pairwise distances, and (ii) pooling data from all populations of each species, and computing a single distance.

\section{Results}

Allele frequencies for each population and the primary data files (genotypes of all individuals) are available at http://ansc.une.edu.au/ansc/genetics/ link through Barker JSF. One locus $\left(\mathrm{Sh} 0^{+}\right)$did not amplify satisfactorily in two S. hibisci populations, and this and two other loci (Sh29c and Sh88 ${ }^{+}$) did not amplify in S. aclinata. For the remaining 17 loci in the two species, the mean numbers of alleles/locus/population were, for

S. hibisci and S. aclinata respectively, 5.38 and 1.24 for the X-linked loci, and 9.16 and 5.18 for the autosomal, both significantly less for $S$. aclinata $(P<0.01$, Kruskal-Wallis ANOVA). For seven loci (Sh8, Sh13, Sh34d, Sh48, Sh78, Sh81 and Sh94), the same allele was at the highest frequency in all or most populations of both species, but for other loci allele frequency distributions were often markedly different. There were no significant differences among populations of either species for either number of alleles per locus or observed heterozygosity.

Over the 17 loci in both species, a total of 253 alleles were detected (Table 1), with 82 in both species and 160 only in S. hibisci. However, the alleles found in S. aclinata were not just a subset of those in S. hibisci, as 11 alleles (in five loci) were found only in S. aclinata. One allele (at locus Sh8ii) was fixed or near to fixation in all S. aclinata populations, while four were present at low frequency in all five $S$. aclinata populations.

Average gene diversity (expected heterozygosity) within populations also was significantly less for S. aclinata $(P<0.01$, Kruskal-Wallis ANOVA), although five loci (Sh8, Sh13, Sh49, Sh88 and Sh94) had similar estimates in both species (Table 1). The reduction in average number of alleles and in heterozygosity for S. aclinata was much greater for the X-linked loci than for the autosomal. Using Mann-Whitney tests, the differences between X-linked and autosomal loci for number of alleles and expected heterozygosity were significant (both $P<0.05$ ), in contrast to no significant differences for S. hibisci. Average expected heterozygosities for all populations within each species were very similar - S. hibisci range: 0.625-0.699, and S. aclinata range: $0.323-0.363$.

Significance of deviations from Hardy-Weinberg expectations was tested using the raw genotype frequencies (ie not corrected for unrecognized null heterozygotes), so results for those locus/population combinations with null homozygotes present are biased toward heterozygote deficiency (Tables 2 and 3). While the proportion of significant tests for these loci in S. hibisci $(35 / 70=0.5)$ is greater than for the other loci $(28 / 108=0.259)$, a number of locus/population combinations without nulls are significant, while others with nulls are not significant (Table 2). Across all loci, all significant tests show an observed heterozygote deficiency, while global tests over the loci where no null homozygotes were detected were highly significant $(P<0.001)$ for all populations except TYA $(P<0.05)$. In all populations, all or most loci showed observed heterozygote deficiency. For the X-linked loci, genotype frequencies in females were generally in HardyWeinberg equilibrium (26/27 for loci without nulls, $12 / 18$ for loci with nulls), but allele frequencies differed significantly between the sexes in $18.5 \%(5 / 27)$ of cases for loci without nulls, and $11.1 \%$ (2/18) for loci with nulls.

In strong contrast to the results for S. hibisci, only 8/55 (14.5\%) of tests for deviation from Hardy-Weinberg equilibrium were significant for $S$. aclinata (Table 3 - three in TJF and three for Sh90, where null homozygotes were segregating), with all significant tests again showing an observed heterozygote deficiency. Global tests were not significant for MEC, but were significant for the other populations (PET $-P<0.05, \mathrm{CAH}-\mathrm{P}<0.01$, DDJ and TJF $-P<0.001)$. None of the significant tests 
Table 1 Number of alleles and average expected heterozygosity per locus for S. hibisci and S. aclinata

\begin{tabular}{|c|c|c|c|c|c|c|}
\hline \multirow[t]{2}{*}{ Locus } & \multicolumn{3}{|c|}{ Number of alleles } & \multirow[t]{2}{*}{ Total } & \multicolumn{2}{|c|}{ Expected heterozygosity } \\
\hline & S. hibisci & S. aclinata & S. aclinata only & & S. hibisci & S. aclinata \\
\hline \multicolumn{7}{|l|}{ X-linked loci } \\
\hline Sh9 & 18 & 3 & & 18 & 0.696 & 0.142 \\
\hline Sh72 & 9 & 1 & & 9 & 0.661 & 0.000 \\
\hline Sh74 & 5 & 2 & & 5 & 0.423 & 0.013 \\
\hline Sh78 & 7 & 2 & & 7 & 0.446 & 0.007 \\
\hline Sh89 & 18 & 1 & & 18 & 0.732 & 0.000 \\
\hline \multicolumn{7}{|l|}{ Autosomal loci } \\
\hline Sh8i & 9 & 8 & 3 & 12 & 0.745 & 0.744 \\
\hline Sh8ii & 20 & 4 & 4 & 24 & 0.840 & 0.019 \\
\hline Sh13 & 12 & 10 & & 12 & 0.818 & 0.822 \\
\hline Sh29c & 12 & - & & & 0.673 & - \\
\hline Sh34d & 7 & 2 & & 7 & 0.546 & 0.344 \\
\hline Sh36c & 23 & 6 & & 23 & 0.859 & 0.538 \\
\hline Sh38d & 17 & 5 & & 17 & 0.781 & 0.606 \\
\hline Sh48 & 4 & 2 & & 4 & 0.018 & 0.009 \\
\hline Sh49 & 35 & 14 & & 35 & 0.883 & 0.821 \\
\hline Sh81 & 13 & 1 & & 13 & 0.594 & 0.000 \\
\hline Sh88 & 26 & 18 & 1 & 27 & 0.883 & 0.815 \\
\hline Sh $88^{+}$ & 13 & - & & & 0.606 & - \\
\hline Sh90 & 8 & 5 & 1 & 9 & 0.707 & 0.241 \\
\hline Sh94 & 11 & 9 & 2 & 13 & 0.603 & 0.660 \\
\hline Mean $( \pm S D)$ & $14.2(8.4)^{\mathrm{b}}$ & $5.5(4.9)$ & & $14.9(8.5)$ & $0.659(0.206)$ & $0.340(0.344)$ \\
\hline X-linked loci - mean $( \pm S D)$ & $11.4(6.2)$ & $1.8(0.8)$ & & $11.4(6.2)$ & $0.592(0.146)$ & $0.032(0.062)$ \\
\hline Autosomal loci - mean $( \pm S D)$ & $15.4(9.1)^{\mathrm{b}}$ & $7.0(5.1)$ & & $16.3(9.1)$ & $0.683(0.223)$ & $0.468(0.331)$ \\
\hline
\end{tabular}

aExpected heterozygosity for $\mathrm{X}$-linked loci estimated from female data only.

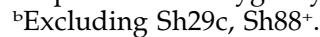

were for X-linked loci, but allele frequencies differed significantly between the sexes in $12.5 \%(1 / 8)$ of cases.

For both species, no genotypic linkage disequilibrium tests within populations were significant after Bonferroni correction.

Over all nine S. hibisci populations (378 individuals), 79 different haplotypes for Sh8i and Sh8ii were estimated. The correlation coefficient between allele sizes of the two loci was $-0.020(P=0.59)$, and for the permutation test of the covariance, the probability of getting the observed value by chance was 0.305 .

As with the Hardy-Weinberg tests within populations, the overall F-statistics show generally positive $f\left(F_{\mathrm{IS}}\right)$ values (Tables 4,5 ). Mean $f$ values are not significantly different between those loci where no null homozygotes were detected and those where null heterozygote frequencies were estimated assuming Hardy-Weinberg equilibrium (S. hibisci: 0.170 and 0.152, Table 4; S. aclinata: 0.107 and 0.045 , Table 5). It would be expected that the latter loci should have $f$ values not significantly different from zero, but there could still be deficiencies of heterozygotes for the non-null alleles. There were more loci with significant $f$ estimates, and higher mean values for S. hibisci than for S. aclinata (Tables 4 and 5). For both species, $\theta\left(F_{\mathrm{ST}}\right)$ estimates show significant differentiation among populations, but the magnitude of the differentiation is 2-3 times greater for $S$. hibisci. Neither species showed a significant pattern of isolation by distance $(P=0.332$ and 0.070 for S.hibisci and S. aclinata, respectively). For both species, genotypic differentiation of populations was highly significant $(P<0.001)$. Pairwise $\theta$ estimates (based on the loci in part 1 of Tables 4 and 5) show for S. hibisci (Table 6) that two populations (CHM and CAR-S) are each significantly differentiated from each other and from all other populations. In contrast, three of the central Queensland populations (BCY, BNP, YBR) are not significantly different from each other, nor from the two southernmost populations (BAL, TAR). Similarly for S. aclinata, where geographic distances among the populations are much less, some that are geographically close (MEC, DDJ) are significantly different, while more distant populations are not (Table 6). Pairwise estimates of genotypic differentiation (Table 6) showed more differentiation among populations, but were generally in accord with the estimates of $\theta$.

The BOTTLENECK analysis (results not shown), using the TPM model that is most appropriate for microsatellites, found that, rather than heterozygosity excess (ie expected heterozygosity greater than that expected from the observed number of alleles - Cornuet and Luikart, 1996) as expected with past bottlenecks, all populations of S. hibisci (except YBR) have a significant heterozygosity deficiency, while no populations of S. aclinata are significant (except TJF for the Wilcoxin test).

The neighbour-joining tree including both species (Figure 2) shows a clear separation of the species, and for S. hibisci no clustering of populations from the same Hibiscus species. CAR-S and CHM, the populations most genetically distinct from the others, also are the most geographically separated from the other populations.

For the two pairs of $S$. hibisci populations from different Hibiscus species but in close proximity, both pairwise genotypic differentiation and $D_{\mathrm{A}}$ genetic distances show differentiation between the populations of each pair similar to that between these populations that were from the same Hibiscus species, but far distant 
Table 2 Significant tests of deviation from Hardy-Weinberg equilibrium for S. hibisci (females only for X-linked loci): (1) 12 loci where no null homozygotes were detected (Sh9 null individuals in males only), and (2) eight loci where null homozygotes were segregating (including Sh $90^{+}$, which was not assayed in two populations)

\begin{tabular}{|c|c|c|c|c|c|c|c|c|c|}
\hline Locus & $\mathrm{CHM}$ & $B C S$ & $B C Y$ & $B N P$ & $Y B R$ & CAR-S & TYA & $B A L$ & TAR \\
\hline \multicolumn{10}{|l|}{ (1) } \\
\hline Sh8i & $0.682^{* * *}$ & $0.602^{* * *}$ & & $0.172^{*}$ & $0.467^{* * *}$ & $0.369^{* *}$ & & $0.438^{* * *}$ & \\
\hline $\operatorname{Sh} 9^{x}$ & & & $\mathrm{~N}^{\mathrm{a}}$ & & & $N, S^{* b}$ & & & $\mathrm{~N}$ \\
\hline \multicolumn{10}{|l|}{ Sh13 } \\
\hline Sh29c & $0.441^{* *}$ & $0.324^{* *}$ & $0.335^{* * *}$ & $0.274^{*}$ & & $0.231^{*}$ & & $0.116^{* * *}$ & $0.463^{* *}$ \\
\hline Sh38d & & & & & & $0.282^{* *}$ & & & $0.316^{*}$ \\
\hline Sh48 & $\mathrm{H}^{\mathrm{c}}$ & & $\mathrm{H}$ & $\mathrm{H}$ & $\mathrm{M}^{\mathrm{d}}$ & M & $\mathrm{H}$ & M & $\mathrm{H}$ \\
\hline Sh49 & $0.585^{* * *}$ & & $0.179^{*}$ & & & $0.324^{* * *}$ & & & \\
\hline Sh $72^{x}$ & $\mathrm{~S}^{*}$ & & $\mathrm{~S}^{*}$ & & & $S^{*}$ & & & \\
\hline \multirow[t]{2}{*}{$\operatorname{Sh} 78^{x}$} & & & & & & $0.709^{* * *}$ & & & \\
\hline & & & & & & $S^{* *}$ & & & \\
\hline Sh81 & & & & & & & & $0.231^{*}$ & \\
\hline Sh 88 & & $0.360^{* * *}$ & & $0.242^{*}$ & $0.275^{*}$ & & & $0.396^{* * *}$ & $0.309^{* * *}$ \\
\hline Sh94 & $0.427^{* * *}$ & & $0.403^{* *}$ & $0.365^{* *}$ & & & & & \\
\hline Global (over loci) probability & $* * *$ & $* * *$ & $* * *$ & $* * *$ & $* * *$ & $* * *$ & * & $* * *$ & $* * *$ \\
\hline \multicolumn{10}{|l|}{ (2) } \\
\hline \multirow[t]{2}{*}{ Sh8ii } & & $0.582^{* * *}$ & & $0.260^{* *}$ & & $0.249^{* * *}$ & & & \\
\hline & & $\mathrm{N}$ & & $\mathrm{N}$ & $\mathrm{N}$ & & $\mathrm{N}$ & & \\
\hline Sh34d & $\begin{array}{c}0.408^{* *} \\
\mathrm{~N}\end{array}$ & $0.524^{* *}$ & $0.715^{* * *}$ & $0.420^{* *}$ & $\begin{array}{c}0.469^{* *} \\
\mathrm{~N}\end{array}$ & & & $\begin{array}{c}0.651^{* * *} \\
\mathrm{~N}\end{array}$ & $\begin{array}{c}0.542^{* * * *} \\
\mathrm{~N}\end{array}$ \\
\hline Sh36c & $\begin{array}{c}0.547^{* * *} \\
\mathrm{~N}\end{array}$ & $0.415^{* * *}$ & $0.352^{* * *}$ & $0.474^{* * *}$ & $0.484^{* * *}$ & $0.520^{* * *}$ & $\begin{array}{c}0.450^{* * * *} \\
\mathrm{~N}\end{array}$ & $0.512^{* * *}$ & $0.551^{* * * *}$ \\
\hline \multirow[t]{2}{*}{ Sh74 $4^{x}$} & $0.750^{* * *}$ & & & & $1.000^{* * *}$ & & $0.489^{*}$ & $0.748^{*}$ & $0.720^{* *}$ \\
\hline & $\mathrm{N}$ & $\mathrm{N}$ & & $N, S^{* *}$ & $\mathrm{~N}$ & $N, S^{* *}$ & & $\mathrm{~N}$ & $\mathrm{~N}$ \\
\hline \multirow[t]{2}{*}{ Sh $88^{+}$} & $0.358^{* * *}$ & & & & & & & $0.609^{* * *}$ & \\
\hline & $\mathrm{N}$ & $\mathrm{N}$ & & & $\mathrm{N}$ & & & $\mathrm{N}$ & \\
\hline \multirow[t]{2}{*}{ Sh $89^{x}$} & & & & & & & & $0.489^{* * *}$ & \\
\hline & & & $\mathrm{N}$ & $\mathrm{N}$ & & & & $\mathrm{N}$ & \\
\hline \multirow[t]{2}{*}{ Sh90 } & $0.680^{* * *}$ & $0.412^{* * *}$ & $0.404^{* * *}$ & $0.259^{* *}$ & $0.419^{* * *}$ & $0.203^{* *}$ & & $0.668^{* * *}$ & \\
\hline & $\mathrm{N}$ & $\mathrm{N}$ & $\mathrm{N}$ & $\mathrm{N}$ & $\mathrm{N}$ & $\mathrm{N}$ & $\mathrm{N}$ & N & $\mathrm{N}$ \\
\hline \multirow[t]{2}{*}{ Sh90+ } & $0.610^{* * *}$ & & & & & & & & \\
\hline & $\mathrm{N}$ & & $\mathrm{N}$ & & $\mathrm{N}$ & na & na & & \\
\hline
\end{tabular}

Figures given for significant tests are $f$ values (Weir and Cockerham, 1984).

na - not assayed. ${ }^{*} P<0.05,{ }^{* *} P<0.01,{ }^{* * *} P<0.001$.

The superscript letter ' $x$ ' denotes $X$-linked loci.

${ }^{a} \mathrm{~N}$ - null allele segregating.

bS - for X-linked loci, significant genic differentiation between the sexes.

${ }^{\mathrm{c}} \mathrm{H}$ - only one heterozygote in sample.

${ }^{\mathrm{a}} \mathrm{M}$ - monomorphic.

( $\cong 1500 \mathrm{~km}$ ) from each other (Table 7). Four loci showed significant pairwise genotypic differentiation for one of the nearby but different Hibiscus species comparisons, and also significant differentiation for one or other of the distant but same Hibiscus species pairs. For each of two loci (Sh38d and Sh89) the nearby BCY and BCS populations showed significant differentiation (both $P<0.01$ ), but differentiation was not significant for either of the distant but same Hibiscus species comparisons. Pairwise $\theta$ estimates show strong differentiation for the nearby BCY and BCS populations, but not for BAL and TAR.

\section{Divergence time of the two species}

The $D_{\mathrm{S}}$ distance estimates for the average over 45 pairwise distances and for the pooled populations of each species were 0.620 and 0.603 , respectively. For $D_{\mathrm{TL}}$, the estimates were 0.501 and 0.365 . These estimates were made using the raw genotype data, but an estimate of $D_{\mathrm{S}}$ also was obtained using the allele frequencies after correction for the presence of null alleles, and the average over the 45 pairwise distances was 0.606 .
Of the 17 loci, four are pure dinucleotide repeats and the other 13 are interrupted pure, compound (one interrupted) or complex (one interrupted) (nomenclature according to Chambers and MacAvoy, 2000). Based on the estimate of Schug et al (1998) of a dinucleotide mutation rate of $9.3 \times 10^{-6}$ in $D$. melanogaster, with triand tetranucleotide rates 6.4-8.4 times slower, and the Zhu et al (2000) finding of a lower rate for imperfect repeats, a mutation rate of $1 \times 10^{-6}$ is assumed. Assuming 10 generations per year, divergence time estimates were: for the average of 45 pairwise distances and for pooled populations - $D_{\mathrm{S}} 31000$ and 30150 years, respectively, and for $D_{\mathrm{TL}} 25050$ and 18250 years. For five generations per year, these estimates would be doubled.

\section{Discussion}

Genetic variability analyses

Variability is much higher for S. hibisci, both for number of alleles/locus and expected heterozygosity (Table 1). Although the expected heterozygosity $\left(H_{\mathrm{E}}\right)$ depends on 
Table 3 Significant tests of deviation from Hardy-Weinberg equilibrium for S. aclinata (females only for X-linked loci)

\begin{tabular}{lccccc}
\hline Locus & MEC & CAH & PET & DDJ & TJF \\
\hline Sh8i & & $0.324^{*}$ & & & \\
Sh8ii & $\mathrm{M}^{\mathrm{a}}$ & $\mathrm{H}^{\mathrm{b}}$ & $\mathrm{H}$ & $\mathrm{M}$ & \\
Sh38d & & & & & $0.302^{*}$ \\
Sh48 & $\mathrm{M}$ & & $\mathrm{M}$ & $\mathrm{M}$ & $\mathrm{M}$ \\
Sh49 & & $0.258^{*}$ & & & $0.176^{*}$ \\
Sh90 & $0.353^{*}$ & $0.702^{* * *}$ & $\mathrm{H}$ & & $0.483^{*}$ \\
& $\mathrm{~N}^{\mathrm{c}}$ & $\mathrm{N}$ & & & $\mathrm{N}$ \\
Sh94 & & & & $0.414^{* * *}$ & \\
\hline
\end{tabular}

Figures given for significant tests are $f$ values (Weir and Cockerham, 1984).

Sh13, Sh34d, Sh36c and Sh88 - no significant deviation in any population.

Sh9 - null allele segregating in PET and DDJ, significant sex difference in allele frequencies in DDJ.

Sh72, Sh81, Sh89- monomorphic in all populations.

Sh74 - females monomorphic in all populations, one null male in each of CAH and PET.

Sh78 - one heterozygote in TJF, other populations monomorphic.

${ }^{\mathrm{a}} \mathrm{M}$ - monomorphic.

${ }^{\mathrm{b}} \mathrm{H}$ - only one heterozygote in sample.

${ }^{\mathrm{C}} \mathrm{N}-$ null allele segregating.

${ }^{*} P<0.05,{ }^{* * *} P<0.001$.

Table 4 F-statistics analyses for S. hibisci: (1) 12 loci where no null homozygotes were detected in any population (significance from permutation tests in the FSTAT program) and (2) seven loci where null homozygotes were segregating (significance from $t$-test using estimated standard deviation)

\begin{tabular}{|c|c|c|c|}
\hline Locus $^{\mathrm{a}}$ & $\mathrm{f}\left(\mathrm{F}_{I S}\right)$ & $\theta\left(\mathrm{F}_{S T}\right)$ & $\mathrm{F}\left(\mathrm{F}_{I T}\right)$ \\
\hline \multicolumn{4}{|l|}{ (1) } \\
\hline Sh $8 \mathrm{i}$ & $0.354(0.065)^{* * *}$ & $0.000(0.004)$ & $0.354(0.065)^{* * *}$ \\
\hline Sh9 $9^{x}$ & $0.064(0.028)$ & $0.011(0.010)^{* *}$ & $0.074(0.026)$ \\
\hline Sh13 & $0.026(0.027)$ & $0.004(0.005)$ & $0.029(0.028)$ \\
\hline Sh29c & $0.288(0.038)^{* * *}$ & $0.051(0.022)^{* * *}$ & $0.324(0.043)^{* * * *}$ \\
\hline Sh38d & $0.159(0.033)^{* * *}$ & $0.002(0.005)$ & $0.161(0.033)^{* * * *}$ \\
\hline Sh48 & $-0.004(0.004)$ & $-0.002(0.003)$ & $-0.006(0.002)$ \\
\hline Sh49 & $0.189(0.061)^{* * * *}$ & $0.029(0.017)^{* * *}$ & $0.214(0.072)^{* * * *}$ \\
\hline $\operatorname{Sh} 72^{x}$ & $0.040(0.047)$ & $0.012(0.008)$ & $0.051(0.047)$ \\
\hline Sh78x & $0.139(0.120)$ & $0.039(0.025)^{* * *}$ & $0.174(0.131)^{*}$ \\
\hline Sh81 & $0.160(0.032)^{* * *}$ & $0.008(0.007)$ & $0.167(0.034)^{* * *}$ \\
\hline Sh 88 & $0.241(0.036)^{* * *}$ & $0.005(0.004)$ & $0.245(0.037)^{* * * *}$ \\
\hline Sh94 & $0.185(0.068)^{* * *}$ & $0.001(0.004)$ & $0.186(0.070)^{* * *}$ \\
\hline Mean $^{\mathrm{b}}$ & $0.170(0.032)^{* * *}$ & $0.014(0.005)^{* * *}$ & $0.181(0.033)^{* * *}$ \\
\hline \multicolumn{4}{|l|}{ (2) } \\
\hline Sh8ii & $0.100(0.040)^{*}$ & $0.027(0.015)$ & $0.125(0.044)^{* *}$ \\
\hline Sh34d & $0.188(0.082)^{*}$ & $0.107(0.056)$ & $0.274(0.079)^{* * * *}$ \\
\hline Sh36c & $0.310(0.077)^{* * *}$ & $0.027(0.008)^{* *}$ & $0.328(0.072)^{* * * *}$ \\
\hline $\operatorname{Sh} 74^{x}$ & $0.146(0.091)$ & $0.049(0.017)^{* *}$ & $0.188(0.094)^{*}$ \\
\hline Sh $88^{+}$ & $0.114(0.037)^{* *}$ & $0.124(0.043)^{* *}$ & $0.225(0.056)^{* * *}$ \\
\hline Sh $89^{x}$ & $0.181(0.052)^{* * *}$ & $0.007(0.014)$ & $0.187(0.051)^{* * * *}$ \\
\hline Sh90 & $-0.013(0.010)$ & $0.031(0.017)$ & $0.018(0.023)$ \\
\hline Mean $^{\mathrm{b}}$ & $0.152(0.044)^{* * * *}$ & $0.049(0.016)^{* *}$ & $0.193(0.043)^{* * *}$ \\
\hline
\end{tabular}

The superscript letter ' $\mathrm{x}$ ' denotes $\mathrm{X}$-linked loci.

aStandard deviation in parentheses - estimate from jackknife over populations.

bStandard deviation in parentheses - estimate from jackknife over loci.

${ }^{*} P<0.05,{ }^{* *} \mathrm{P}<0.01, * * * P<0.001$.

allele frequencies, increasing number of alleles generally leads to increased $H_{\mathrm{E}}$. Thus, differences in $H_{\mathrm{E}}$ between the two species for any given locus are largely a function of differences in the number of alleles.
Table 5 F-statistics analyses for S. aclinata: (1) 10 loci where no null homozygotes were detected in any population (significance from permutation tests in the FSTAT program) and (2) two loci where null homozygotes were segregating (significance from $t$-test using estimated standard deviation)

\begin{tabular}{lccc}
\hline Locus $^{\mathrm{a}}$ & $\mathrm{f}\left(\mathrm{F}_{I S}\right)$ & $\theta\left(\mathrm{F}_{S T}\right)$ & $\mathrm{F}\left(\mathrm{F}_{I T}\right)$ \\
\hline (1) & & & \\
Sh8i & $0.228(0.030)^{* *}$ & $0.001(0.006)$ & $0.229(0.033)^{* *}$ \\
Sh8ii & $0.633(0.490)$ & $-0.005(0.003)$ & $0.631(0.491)^{*}$ \\
Sh9 & $0.147(0.172)$ & $-0.025(0.004)$ & $0.125(0.172)$ \\
Sh13 & $-0.047(0.029)$ & $0.012(0.011)$ & $-0.034(0.032)$ \\
Sh34d & $0.198(0.073)$ & $-0.006(0.005)$ & $0.192(0.070)^{*}$ \\
Sh38d & $0.116(0.059)$ & $-0.008(0.002)$ & $0.108(0.059)$ \\
Sh48 & $-0.022(0.010)$ & $0.022(0.010)$ & 0 \\
Sh49 & $0.114(0.054)^{* *}$ & $0.012(0.010)^{* *}$ & $0.125(0.045)^{* * *}$ \\
Sh88 & $0.027(0.030)$ & $0.010(0.006)$ & $0.037(0.031)$ \\
Sh94 & $0.194(0.073)^{* *}$ & $0.013(0.008)^{*}$ & $0.205(0.071)^{* *}$ \\
Mean & 0.107(0.041) & $0.006(0.003)^{* * * *}$ & $0.112(0.040)^{* * *}$ \\
& & & \\
(2) & & & $0.047(0.034)$ \\
Sh36c & $0.045(0.042)$ & $0.002(0.011)$ & $0.109(0.044)^{* *}$ \\
Sh90 & $0.044(0.015)^{* *}$ & $0.069(0.048)$ & $0.059(0.037)$ \\
Mean ${ }^{\text {b }}$ & $0.045(0.001)^{* * * *}$ & $0.015(0.040)$ & \\
\hline
\end{tabular}

The superscript letter ' $\mathrm{x}$ ' denotes $\mathrm{X}$-linked loci.

aStandard deviation in parentheses - estimate from jackknife over populations.

${ }^{\mathrm{b}}$ Standard deviation in parentheses - estimate from jackknife over loci.

${ }^{*} P<0.05,{ }^{* *} P<0.01,{ }^{* * *} P<0.001$

\section{Hardy-Weinberg equilibrium and null alleles}

A striking feature of the results is the large number of significant deviations from Hardy-Weinberg equilibrium in the S. hibisci populations (Table 2). However, these tests used the observed numbers of each genotype, so that for those loci where null homozygotes were found the number of heterozygotes is underestimated (ie heterozygotes for the null allele are not recorded). Thus, the test results were given separately for loci without and with null homozygotes present (Tables 2, 3). However, an analysis to check Mendelian segregation of the microsatellite loci in S. hibisci (Wilson et al, unpublished) found null alleles at loci additional to those seen in these populations, namely at Sh8i, Sh29c, Sh38d, Sh49, Sh81, Sh88 and Sh94. Thus, there could be undetected null alleles at these loci, particularly as all the seven show significant deviations from Hardy-Weinberg equilibrium in one or more populations.

If null alleles are suspected, but no null homozygotes are detected in the sample assayed, the putative null allele frequency can be estimated from the heterozygote deficiency (Brookfield, 1996) as:

$$
\left(H_{\mathrm{E}}-H_{\mathrm{O}}\right) /\left(1+H_{\mathrm{E}}\right)
$$

where $H_{\mathrm{O}}$ and $H_{\mathrm{E}}$ are the observed and expected heterozygosities, and panmixia is assumed. Using this formula, the estimated null allele frequencies for each of the 28 cases of significant deviation from HardyWeinberg equilibrium in Table 2, part 1 range from 0.046 to 0.288 , which are generally within the range of estimated null allele frequencies at the loci where nulls were detected. At a null allele frequency of 0.154 , one null homozygote would be expected in a sample of 42 individuals. Out of the 28 cases, 15 had an estimated null allele frequency less than this, so that these deviations could be due to undetected null alleles. At the extreme 
Table 6 Pairwise population differentiation $(\theta)$ estimates above the diagonal, and pairwise geographic distances $(\mathrm{km})$ below

\begin{tabular}{|c|c|c|c|c|c|c|c|c|c|}
\hline \multicolumn{10}{|c|}{ S. hibisci } \\
\hline & CHM & $B C S$ & $B C Y$ & $B N P$ & $Y B R$ & $C A R-S$ & $T Y A$ & $B A L$ & $T A R$ \\
\hline CHM & & $0.037^{*}$ & $0.019 *$ & $0.034^{*}$ & $0.032^{*}$ & $0.032^{*}$ & $0.025^{*}$ & $0.019^{*}$ & $0.027^{*}$ \\
\hline BCS & 574 & & $0.014 *$ & 0.008 & $0.011^{*}$ & $0.011^{*}$ & $0.014^{*}$ & $0.011^{*}$ & 0.003 \\
\hline $\mathrm{BCY}$ & 574 & 1.2 & & 0.013 & $\overline{0.006}$ & $0.019 *$ & $0.015^{*}$ & 0.008 & $\overline{0.003}$ \\
\hline BNP & 876 & 304 & 304 & & 0.005 & $0.018^{*}$ & 0.011 & 0.009 & 0.004 \\
\hline YBR & 888 & 314 & 314 & 19 & & $0.018^{*}$ & 0.012 & 0.006 & -0.003 \\
\hline CAR-S & 978 & 471 & 470 & 358 & 342 & & $0.019^{*}$ & $0.017^{*}$ & $0.012^{*}$ \\
\hline TYA & 1562 & 991 & 990 & 702 & 686 & 658 & & 0.004 & 0.006 \\
\hline BAL & 2046 & 1521 & 1521 & 1289 & 1270 & 1069 & 693 & & -0.001 \\
\hline TAR & 2046 & 1521 & 1521 & 1288 & 1270 & 1069 & 692 & 2.1 & \\
\hline
\end{tabular}

S. aclinata

\begin{tabular}{|c|c|c|c|c|c|}
\hline & $M E C$ & $C A H$ & PET & $D D J$ & TJF \\
\hline MEC & & 0.003 & $0.011^{*}$ & $0.007^{*}$ & 0.003 \\
\hline $\mathrm{CAH}$ & 6 & & 0.003 & $0.010^{*}$ & 0.001 \\
\hline PET & 259 & 260 & & $\overline{0.007}$ & 0.007 \\
\hline DDJ & 12 & 16 & 251 & & $0.004^{*}$ \\
\hline $\mathrm{TJF}$ & 257 & 258 & 17 & 248 & \\
\hline
\end{tabular}

Significant pairwise genotypic differentiation is also shown - indicated by $\theta$ values in bold $(P<0.001)$, italic $(P<0.01)$ and underlined $(P<0.05)$.

${ }^{*} P<0.05,{ }^{* *} P<0.01,{ }^{* * *} P<0.001$ - significance of $\theta$ tested by permutation of genotypes among populations (10000 times).

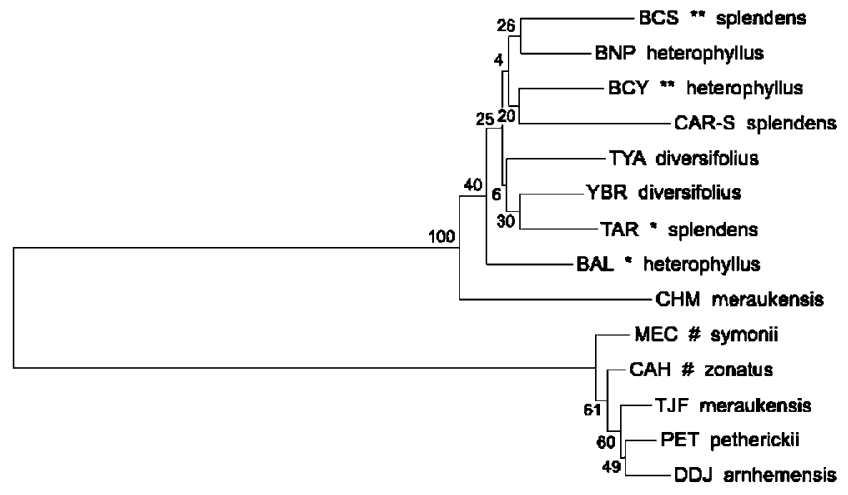

Figure 2 Neighbour-joining tree for $S$. hibisci and S. aclinata populations, and the Hibiscus species at each of these localities. Populations of S. hibisci (S. aclinata) with the same superscript symbol are located within $2 \mathrm{~km}(\#-6 \mathrm{~km})$ of each other.

estimated null allele frequency of $0.288,3.5$ null homozygotes would be expected in a sample of 42 individuals, but the probability that none would be seen is not particularly low.

This probability of getting no null homozygotes in a sample of 42 individuals from an infinite population with true null homozygote frequency of $x$ is $(1-x)^{42}$. For true null homozygote frequencies of $0.0238,0.0476$ and 0.0714 , corresponding to one, two or three such individuals expected in a sample of 42 , the probabilities are $0.364,0.129$ and 0.045 , and these probabilities are not much reduced by sampling from a large finite population, for example, sampling from 1000 individuals, the probability of not seeing one null homozygote, when the population frequency is $3 / 42$, is 0.042 .

Similarly, $f\left(F_{\mathrm{IS}}\right)$ values for those loci where no null homozygotes were detected (Tables 4 and 5 - part 1 in each) will be inflated if null alleles are present in the sample, but not detected. The significant $f\left(F_{\mathrm{IS}}\right)$ values were only for those seven loci where null alleles were found in the segregation analyses (Wilson et al, unpublished). Thus, it is likely that much of the significant deviation from Hardy-Weinberg equilibrium and significant positive $f$ values at these loci can be attributed to undetected null alleles. For S. aclinata, all cases of significant deviations from Hardy-Weinberg equilibrium and significant $f$ (except Sh90) could be attributed to undetected null alleles, assuming null alleles occur at the same loci in S. aclinata as in S. hibisci.

Significant $f\left(F_{\text {IS }}\right)$ values for the loci where null homozygotes were detected (Tables 2 and 3 - part 2) would not be expected, as these estimates were obtained from genotype frequency data after estimation of null heterozygote frequencies. As this procedure assumes panmixia, the significant positive $f$ values for these loci are likely due to deficiencies of heterozygotes for the non-null alleles. However, $f$ values are global (over populations) estimates, and the effect of estimating null heterozygote frequencies will vary among loci, depending on the number of alleles, and on the number of populations where null homozygotes were found. Overall, it would seem most parsimonious to conclude that these populations of both species are panmictic. However, the results should raise a strong note of caution in population studies where significant deviations from Hardy-Weinberg equilibrium may be due to undetected null alleles, or where the presence of null alleles is inferred only from the population data.

\section{Ascertainment bias}

A number of studies have shown that microsatellite alleles are longer and more variable in the species from which they were cloned, and Ellegren et al (1995) and Forbes et al (1995) proposed that the identification of microsatellite loci by DNA library screens selects for longer loci (ascertainment bias). Here, however, the mean allele size is greater in S. aclinata for eight loci, and for S. hibisci in nine, and the differences are not significant 
Table 7 Genetic differentiation between geographically close populations of $S$. hibisci breeding on different Hibiscus species, as compared with differentiation of these populations breeding on the same Hibiscus species, but geographically distant

\begin{tabular}{|c|c|c|c|c|}
\hline & BAL/TAR het/spl ${ }^{\mathrm{a}}$ & $B C Y / B C S$ het $/$ spl & $B A L / B C Y$ het/het & $T A R / B C S \mathrm{spl} / \mathrm{spl}$ \\
\hline Distance $(\mathrm{km})$ & 2.1 & 1.2 & 1521 & 1521 \\
\hline 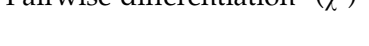 & 30.2 & $67.9^{* * * *}$ & 36.3 & $47.3^{*}$ \\
\hline$D_{\mathrm{A}}$ & 0.081 & 0.087 & 0.081 & 0.089 \\
\hline Pairwise $\theta$ & -0.001 & $0.014^{*}$ & 0.008 & 0.003 \\
\hline
\end{tabular}

${ }^{a}$ het $=H$. heterophyllus, $\mathrm{spl}=H$. splendens.

${ }^{\mathrm{b}}$ Genotypic differentiation - estimated using GENEPOP.

${ }^{*} P<0.05,{ }^{* * *} P<0.001$.

for any locus. Further, the S. aclinata-specific alleles were equally at or near the upper size range and the lower size range. Thus, we have no evidence for ascertainment bias.

In a reciprocal test of ascertainment bias in D. melanogaster and D. simulans, Hutter et al (1998) found both number of alleles and expected heterozygosity to be significantly higher in the species from which the microsatellite loci were derived, although differences between these species were much less than for S. hibisci and S. aclinata. Thus, differences in population history for these latter species more likely contributed to the marked differences in levels of genetic variability.

\section{Juxtaposed microsatellites}

Previous studies (Pena et al, 1994; Dermitzakis et al, 1998) have found strong linkage disequilibrium between juxtaposed loci, but, in contrast to these studies, S. hibisci shows no linkage disequilibrium and a weak negative, nonsignificant, allele size association. Both previous studies suggest that juxtaposed microsatellites may not evolve independently, but the result for S. hibisci could indicate allele size homoplasy coupled with high rates of microsatellite evolution or long-lived alleles and rare recombination. The general evolutionary features of juxtaposed microsatellites remain to be elucidated.

\section{Population structure}

The BOTTLENECK tests showed that no populations of S. aclinata significantly deviated from expectation, but all populations of $S$. hibisci (except YBR) had a significant heterozygosity deficiency, suggesting that these populations had expanded in size in the last few thousand generations, or that there had been a recent influx of rare alleles from other populations. The latter seems most unlikely, given the magnitude of genetic differentiation among populations and the geographic distances separating most populations. The BOTTLENECK method assumes that the loci are independent, or at least not tightly linked (recombination fraction $>0.1$ ). In all, 16 of the loci have been assigned to three linkage groups (Wilson et al, unpublished), but limited data do not indicate any tight linkages. Further, there was no evidence for linkage disequilibrium, even for the juxtaposed pair, so that any effect of linkage is likely to be very small. The BOTTLENECK method also assumes that all loci are in Hardy-Weinberg equilibrium. Although only those loci that did not show deviations from Hardy-Weinberg equilibrium were used in these tests, undetected null alleles would bias the results towards heterozygosity deficiency. This could account for some of the significant heterozygosity deficiency, but most likely not all, thus implying population size expansion for S. hibisci, but not S. aclinata. The host Hibiscus species for S. hibisci are known as colonizers of disturbed habitats such as forest clearings and edges, and roadsides. In the last few thousand generations of $S$. hibisci, encompassing the period of European settlement in Australia since 1788, individual Hibiscus patches may well have increased in size (number of plants), but at the same time become more isolated through forest clearing and agricultural development. The Hibiscus populations on which S. aclinata breeds in the Northern Territory, in contrast, are located in areas that have not been subject to agricultural development, and have likely been at their present size for a very long time.

These differences in population history between the two species could also contribute to the lower number of alleles in S. aclinata. Allele numbers for X-linked loci are markedly reduced, as are private allele frequencies -5.44 per population for $S$. hibisci and 3.2 per population for $S$. aclinata. Both these results are consistent with greater drift effects (smaller effective size) for S. aclinata populations. The flowering periods for the S. aclinata host species are generally shorter than for the S. hibisci host species, which is likely to produce an annual bottleneck that is smaller for S. aclinata.

Overall estimates of both $\theta$ and genotypic differentiation of populations were significant for both species, although much higher for S. hibisci than for S. aclinata. It might be assumed that this species difference is a function of the much broader geographical distribution of the S. hibisci populations, that is, greater isolation. In fact, it does appear to be an isolation effect, but for only the two populations CAR-S and CHM. Mean $\theta$ values for each of CAR-S and CHM with the other populations are 0.018 and 0.028 respectively, against an overall mean of 0.014. When CAR-S and CHM are excluded, the overall mean $\theta$ is 0.008 , essentially the same as for the overall mean for S. aclinata (0.006 - Table 5). Further, both populations show strong evidence of drift or selection effects on allele frequency distributions. For example, at Sh8ii the allele at highest frequency in CAR-S (0.321) has frequencies of 0.012-0.105 in the other populations, while for Sh34d the third most frequent allele in CHM (0.135) is the highest frequency allele in all other populations (0.486-0.833).

The CAR-S population is located in Carnarvon Gorge (Figure 1), a mesic habitat in contrast to the predominant open forest and grassland of central Queensland. The nearest known Hibiscus populations (H. divaricatus and $H$. splendens) are in similar habitat on the Blackdown Tableland some $160-180 \mathrm{~km}$ to the northeast (records of the Queensland Herbarium). The CAR-S population thus 
is likely a relict population that has been isolated at least since the cool, dry periods of the Pleistocene. CHM, from the northern part of the S. hibisci distribution (Figure 1), is separated from populations to the south by the dry Burdekin gap (Kelemen and Moritz, 1999), which is to the north of the BCS and BCY populations, and this gap also has isolated the northern populations since the Pleistocene.

For the S. hibisci populations (other than CAR-S and CHM) and the $S$. aclinata populations, migration cannot explain the history and current population structure. If migration were an important component, either no population differentiation or isolation by distance would be expected. Neither is true: population differentiation is significant, and no isolation by distance was detected. Indeed as noted earlier, both species show patterns of pairwise population differentiation that are inconsistent with migration.

\section{Host-plant specialization}

Although based on only two pairs of populations breeding on $H$. heterophyllus and $H$. splendens, the early stages of host-race formation possibly have been detected (Table 7). Clearly, this evidence is stronger for $\mathrm{BCY} / \mathrm{BCS}$, where also the results showing that two loci are significantly differentiated for the nearby but different Hibiscus species comparisons, but not significant for the distant but same Hibiscus species comparisons, suggest selectively driven differences. Of course, these microsatellite loci are assumed to be neutral, but they may themselves be, or they may mark regions under selection.

A laboratory experiment (McEvey and Barker, 2001) found no evidence for host-plant specialization in $S$. hibisci, but only for $H$. heterophyllus and $H$. diversifolius and recording only progeny number. Other fitness components such as adult longevity and lifetime progeny numbers may be important, and specialization may not have evolved for all Hibiscus species. Thus, further laboratory studies and analyses of additional nearby population pairs are necessary to test the hypothesis of host-race formation.

All of the northern populations of S. hibisci (Figure 1) are breeding on $H$. meraukensis, a species that also is used by $S$. aclinata in the Northern Territory. Direct comparisons of $S$. hibisci and S. aclinata populations from H. meraukensis would help to elucidate the phylogeography and evolution of these two species. Further, genetic analyses of the northern $S$. hibisci populations breeding on $H$. meraukensis would test whether the genetic differentiation of CHM is entirely a function of isolation and drift, or whether there is some degree of host-plant specialization. Hibiscus meraukensis is known (records of the Queensland Herbarium) from a number of localities in northwest Queensland - the region between the known distributions of $S$. hibisci and $S$. aclinata. This region (the Carpentaria gap), recognized as a phylogeographic break for many species (primarily birds), was fairly arid at the glacial maximum of 20000-15000 years BP (Ford, 1987). It is not known if either S. hibisci or $S$. aclinata are now present and breeding on $H$. meraukensis in this region, but it is hoped that this will be investigated.

\section{Divergence time of the two species}

Can any conclusion be reached on the evolutionary divergence time of S. aclinata and S. hibisci? Clearly, they are closely related. McEvey and Barker (2001) showed them to be partially interfertile, with reduced mating frequency and progeny numbers in $\mathrm{F}_{1}$ inter se matings as compared with parentals, and no progeny from $\mathrm{F}_{2}$ inter se matings. They have the same common allele at seven of 17 microsatellite loci, and share a high proportion of the alleles detected (82 of 253). Of the remaining alleles, 160 were present only in $S$. hibisci, but only 11 were present only in S. aclinata. Given the close relationship between the species, and the lower genetic diversity in S. aclinata, the allele numbers in the two species suggest that S. aclinata was derived from $S$. hibisci, following a strong bottleneck at the time of separation.

Genetic distance estimates $\left(D_{\mathrm{S}}\right.$ and $\left.D_{\mathrm{TL}}\right)$ were similar in magnitude, with estimates from the average of the 45 pairwise estimates higher than those from the pooled population data, as expected (Goldstein et al, 1995). Estimated divergence times range from $18250\left(D_{\mathrm{TL}}\right.$, pooled populations, 10 generations per year) to 62000 years $\left(D_{S}\right.$, average of pair-wise distances, five generations per year), with an average of the eight estimates of 39169 years. A divergence time of 40000 years would put it prior to the glacial maximum at 20000-15000 years $\mathrm{BP}$ when the Carpentaria gap was less arid, so that movement across this area was likely to be possible. However, given uncertainty regarding the appropriate mutation model, the mutation rate, constraints on allele size distribution and particularly size homoplasy, the true divergence time may be much longer.

\section{Acknowledgements}

This research was part of a larger collaborative program on the reproductive biology and evolution of $S$. hibisci funded by a grant from the NSF (INT-9512767) to WT Starmer and LL Wolf. Scientists from Australia (JSF Barker), Canada ( MA Lachance, J Bowles) and the USA (M Polak, WT Starmer, LL Wolf) took part in field observations and collections of the populations. The laboratory work reported here was supported by an Australian Research Council grant and a University of New England research grant. I am indebted to Yean Wang and Pam Flynn for technical assistance, to L Craven and B Pfieil for advice on Hibiscus taxonomy, and to V Loeschcke, WT Starmer and P Sunnucks for helpful comments on the manuscript.

\section{References}

Barker JSF (2003). Ecology of two Scaptodrosophila flower breeding species. Drosophila Inf Serv 86: 38-40.

Berlocher SH, Feder JL (2002). Sympatric speciation in phytophagous insects: Moving beyond controversy? Ann Rev Entomol 47: 773-815.

Brookfield JFY (1996). A simple new method for estimating null allele frequency from heterozygote deficiency. Mol Ecol 5 453-455.

Chambers GK, MacAvoy ES (2000). Microsatellites: consensus and controversy. Comp Biochem Physiol Part B 126: 455-476.

Cook RM, Parsons PA, Bock IR. (1977). Australian endemic Drosophila II. A new Hibiscus-breeding species with its description. Aust I Zool 25: 755-763.

Cornuet JM, Luikart G (1996). Description and power analysis of two tests for detecting recent population bottlenecks from allele frequency data. Genetics 144: 2001-2014.

Dermitzakis ET, Clark AG, Batargias C, Magoulas A, Zouros E (1998). Negative covariance suggests mutation bias in a 
two-locus microsatellite system in the fish Sparus aurata. Genetics 150: 1567-1575.

Ellegren H, Primmer CR, Sheldon BC (1995). Microsatellite 'evolution': directionality or bias? Nature Genetics 11: 360-362.

Etges WJ (2002). Divergence in mate choice systems: does evolution play by rules? Genetica 116: 151-166.

Feder JL, Berlocher SH, Opp SB (1998). Sympatric host-race formation and speciation in Rhagoletis (Diptera:Tephritidae): a tale of two species for Charles D. In: Mopper S, Strauss SY (eds) Genetic Structure and Local Adaptation in Natural Insect Populations. Chapman \& Hall: New York. pp 408-441.

Forbes SH, Hogg JT, Buchanan FC, Crawford AM, Allendorf FW (1995). Microsatellite evolution in congeneric mammals: domestic and bighorn sheep. Mol Biol Evol 12: 1106-1113.

Ford J (1987). Hybrid zones in Australian birds. Еmu 87: 158-178.

Funk DJ, Filchak KE, Feder JL (2002). Herbivorous insects: model systems for the comparative study of speciation ecology. Genetica 116: 251-267.

Goldstein DB, Linares AR, Cavalli-Sforza LL, Feldman MW (1995). Genetic absolute dating based on microsatellites and the origin of modern humans. Proc Natl Acad Sci USA 92: $6723-6727$.

Goudet J (2001). FSTAT, a program to estimate and test gene diversities and fixation indices Version 2.9.3. Available from http://www.unil.ch/izea/softwares/fstat.html.

Hochberg Y (1988). A sharper Bonferroni procedure for multiple tests of significance. Biometrika 75: 800-802.

Hutter CM, Schug MD, Aquadro CF (1998). Microsatellite variation in Drosophila melanogaster and Drosophila simulans: a reciprocal test of the ascertainment bias hypothesis. Mol Biol Evol 15: 1620-1636.

Janz N, Nyblom K, Nylin S (2001). Evolutionary dynamics of host-plant specialization: a case study of the tribe Nymphalini. Evolution 55: 783-796.

Kelemen L, Moritz C (1999). Comparative phylogeography of a sibling pair of rainforest Drosophila species (Drosophila serrata and D. birchii). Evolution 53: 1306-1311.

Lessios HA (1992). Testing electrophoretic data for agreement with Hardy-Weinberg expectations. Marine Biol 112: 517-523.

Mantel N (1967). The detection of disease clustering and a generalized regression approach. Cancer Res 27: 209-220.

McEvey SF, Barker JSF (2001). Scaptodrosophila aclinata: a new Hibiscus flower-breeding species related to S. hibisci (Diptera: Drosophilidae). Records Austr Museum 53: 255-262.

Mopper S, Strauss SY (eds) (1998). Genetic Structure and Local Adaptation in Natural Insect Populations. Chapman \& Hall New York.

Nauta MJ, Weissing FJ (1996). Constraints on allele size at microsatellite loci: implications for genetic differentiation. Genetics 143: 1021-1032.

Nei M (1972). Genetic distance between populations. Am Nat 106: $283-292$

Nei M (1978). Estimation of average heterozygosity and genetic distance from a small number of individuals. Genetics 89 583-590.

Nei M, Tajima F, Tateno Y (1983). Accuracy of estimated phylogenetic trees from molecular data II. Gene frequency data. I Mol Evol 19: 153-170.

Pena SDJ, de Souza KT, de Andrade M, Chakraborty R (1994). Allelic associations of two polymorphic microsatellites in intron 40 of the human von Willebrand factor gene. Proc Natl Acad Sci USA 91: 723-727.

Piry S, Luikart G, Cornuet JM (1999). BOTTLENECK: a computer program for detecting recent reductions in the effective population size using allele frequency data. $J$ Hered 90: 502-503.

Polak M, Starmer WT, Barker JSF (1998). A mating plug and male mate choice in Drosophila hibisci Bock. Anim Behav 56: 919-926.
Polak M, Wolf LL, Starmer WT, Barker JSF (2001). Function of the mating plug in Drosophila hibisci Bock. Behav Ecol Sociobiol 49: 196-205.

Pritchard JK, Feldman MW (1996). Statistics for microsatellite variation based on coalescence. Theor Popul Biol 50: 325-344.

Raymond M, Rousset F (1995). GENEPOP (Version 1.2): population genetics software for exact tests and ecumenicism. J Hered 86: 248-249.

Rousset F (1997). Genetic differentiation and estimation of gene flow from F-statistics under isolation by distance. Genetics 145: 1219-1228.

Saitou N, Nei M (1987). The neighbour-joining method: a new method for reconstructing phylogenetic trees. Mol Biol Evol 4: 406-425.

Schug MD, Hutter CM, Wetterstrand KA, Gaudette MS, Mackay TF, Aquadro CF (1998). The mutation rates of di-, tri- and tetranucleotide repeats in Drosophila melanogaster. Mol Biol Evol 15: 1751-1760.

Sokal RR, Rohlf FJ (1981). Biometry, 2nd edn. W.H. Freeman and Co.: San Francisco.

Starmer WT, Polak M, Wolf LL, Barker JSF (1998). Reproductive characteristics of the flower breeding Drosophila hibisci Bock (Drosophilidae) in eastern Australia: genetic and environmental determinants of ovariole number. Evolution 52: 806-815.

Starmer WT, Polak M, Wolf LL, Barker JSF (2000). Reproductive characteristics of the flower-breeding Drosophila hibisci Bock (Drosophilidae) in eastern Australia: within-population genetic determinants of ovariole number. Heredity 84: 90-96.

Starmer WT, Wolf LL, Barker JSF, Bowles JM, Lachance M-A (1997). Reproductive characteristics of the flower breeding Drosophila hibisci Bock (Drosophilidae) along a latitudinal gradient in eastern Australia: relation to flower and habitat features. Biol J Linn Soc 62: 459-473.

Stephens M, Smith NJ, Donnelly P (2001). A new statistical method for haplotype reconstruction from population data. Am J Hum Genet 68: 978-989.

Takezaki N, Nei M (1996). Genetic distances and reconstruction of phylogenetic trees from microsatellite DNA. Genetics 144: 389-399.

Thomas Y, Bethenod M-T, Pelozuelo L, Frérot B, Bourguet D (2003). Genetic isolation between two sympatric host-plant races of the European corn borer, Ostrinia nubilalis Hübner. I. Sex pheromone, moth emergence timing and parasitism. Evolution 57: 261-273.

Tomiuk J, Guldbrandtsen G, Loeschcke V (1998). Population differentiation through mutation and drift - a comparison of genetic identity measures. Genetica 102/103: 545-558.

Tomiuk J, Loeschcke V (1991). A new measure of genetic identity between populations of sexual and asexual species. Evolution 45: 1685-1694.

Tomiuk J, Loeschcke V (1995). Genetic identity combining mutation and drift. Heredity 74: 607-615.

Via S (2001). Sympatric speciation in animals: the ugly duckling grows up. Trends Ecol Evol 16: 381-390.

Weir BS (1990). Genetic Data Analysis. Sinauer: Sunderland.

Weir BS, Cockerham CC (1984). Estimating F-statistics for the analysis of population structure. Evolution 38: 1358-1370.

Wilson ACC, Sunnucks P, Barker JSF (2002). Isolation and characterization of 20 polymorphic microsatellite loci for Scaptodrosophila hibisci. Mol Ecol Notes 2: 242-244.

Wolf LL, Polak M, Barker JSF, Bowles J, Starmer WT (2000a). Reproductive characteristics of Drosophila hibisci in the Northern Territory, Australia. Biol J Linn Soc 71: 549-562.

Wolf LL, Starmer WT, Polak M, Barker JSF (2000b). Genetic architecture of a wing size measure in Drosophila hibisci from two populations in eastern Australia. Heredity 85: 521-529.

Zhu Y, Queller DC, Strassmann JE (2000). A phylogenetic perspective on sequence evolution in microsatellite loci. J Mol Evol 50: 324-338. 